\title{
NOTA
}

\section{PLANEJAMENTO INTEGRADO DE USO DA TERRA: UMA DISCIPLINA INTEGRADORA NO ENSINO DA AGRONOMIA NA UFRGS ${ }^{(1)}$}

\author{
Elvio Giasson ${ }^{(2)}$, Luiz Fernando Coelho de Souza ${ }^{(2)}$, Renato Levien ${ }^{(2)}$ \\ \& Gustavo Henrique Merten ${ }^{(3)}$
}

\begin{abstract}
RESUMO
A disciplina Planejamento Integrado de Uso da Terra, do Curso de Agronomia da Universidade Federal do Rio Grande do Sul, associa os conhecimentos da área de solos com os demais do Curso de Agronomia, interligando-os e dandolhes consistência e significado. A disciplina vale-se do planejamento integrado para reunir o conhecimento agronômico num projeto de exploração e desenvolvimento sustentável de uma ou mais propriedades rurais por meio de uma seqüência de atividades, assim definidas: caracterização regional, levantamento dos recursos naturais existentes na propriedade, levantamento do seu uso atual, diagnóstico do sistema produtivo e elaboração de uma proposta de exploração sustentável da propriedade, que é apresentada para a comunidade local. Os resultados desta experiência demonstram que a disciplina tem sido muito proveitosa no treinamento e aperfeiçoamento dos estudantes, tendo recebido suporte e apoio por parte do corpo discente, dos agricultores e das organizações envolvidas no processo de planejamento agrícola.
\end{abstract}

Termos de indexação: agronomia, graduação, solos, planejamento, avaliação de terras.

\footnotetext{
(1) Recebido para publicação em agosto de 2004 e aprovado em setembro de 2005.

(2) Professor Adjunto, Departamento de Solos, Faculdade de Agronomia, Universidade Federal do Rio Grande do Sul - UFRGS. Av. Bento Gonçalves 7712, CEP 91501-970 Porto Alegre (RS). E-mail: giasson@ufrgs.br; luiz.coelho@unisol.org.br; renatole@ufrgs.br

(3) Professor Adjunto, Departamento de Obras Hidráulicas, Instituto de Pesquisas Hidráulicas, UFRGS. E-mail: merten@iph.ufrgs.br
} 


\title{
SUMMARY: INTEGRATED LAND USE PLANNING: AN INTEGRATIONAL AGRONOMY COURSE AT THE FEDERAL UNIVERSITY OF RIO GRANDE DO SUL
}

\begin{abstract}
The Integrated Land Use Planning course of the Agronomy School of the Federal University of Rio Grande do Sul State, Porto Alegre, Brazil, associates Soil Science with other courses taught in Agronomy, establishing consistent and meaningful crosslinks. The course uses integrated land use planning to feed the compiled agronomical knowledge into a project of sustainable land use for one or more farms. The following sequence of procedures is used for this purpose: regional characterization, survey of existing natural resources, ascertainment of their actual use, production diagnosis, and elaboration of a project for sustainable farm use, which is presented to the local community. Results showed that the course was most useful to train and improve the students' abilities and was supported by students, farmers and organizations engaged in land use planning.
\end{abstract}

Index terms: agronomy, undergraduate, soil, planning, land evaluation.

\section{INTRODUÇÃO}

O curso de Agronomia da Universidade Federal do Rio Grande do Sul (UFRGS) tem sua proposta calcada na formação do profissional generalista, eclético, capaz de transitar com desenvoltura nas diferentes, complexas e extensas áreas do conhecimento das ciências agrárias. O curso é composto por 71 disciplinas obrigatórias e 16 optativas, exigindo um período médio de formação de 10 semestres. Integram o curso de Agronomia 26 departamentos acadêmicos da universidade, dentre os quais se destaca o Departamento de Solos, que contribui com as disciplinas de Química do Solo, Física do Solo, Biologia do Solo, Manejo do Solo, Gênese e Classificação do Solo, Erosão e Conservação do Solo, Tratores e Seus Motores, Mecanização Agrícola e Planejamento Integrado de Uso da Terra (Beck et al., 2000).

A dificuldade maior num curso dessa magnitude é, sem dúvida, não se afastar de seu princípio formador, que habilita ao formando mover-se entre as diversas áreas do conhecimento agronômico, adaptando-o às exigências do campo profissional. A própria característica do ensino universitário, em sua generalidade compartimentado, é o principal foco das dificuldades para a formação generalista. $\mathrm{O}$ estudante universitário, ao fim do curso, sente enormes dificuldades em reunir os conhecimentos adquiridos a fim de dar-lhes a complementaridade necessária ao exercício profissional.

Diante dessa dificuldade, um grupo de professores do Departamento de Solos propôs e teve aprovada, em 1986, uma disciplina integradora de conhecimentos, que foi denominada Planejamento Integrado de Uso da Terra e que recebeu o código AGR03319, com três créditos e uma carga horária semestral de 45 horas-aula.
Buscavam os idealizadores da nova disciplina associar aos conhecimentos da área de solos os demais do curso de Agronomia, interligando-os, dando-lhes consistência e significado, desvelando ao estudante, futuro profissional, as ligações e religações dos saberes e conhecimentos que, ao longo de 10 semestres de curso, haviam adquirido de forma estanque e compartimentada.

A disciplina vale-se do planejamento integrado da terra para reunir o conhecimento agronômico num projeto de exploração e desenvolvimento sustentável de uma ou mais propriedades rurais selecionadas especialmente para esse fim.

O estudante, no exercício das atividades da disciplina, vale-se de todos os conhecimentos até ali adquiridos, identificando potenciais, limitações e interações com o meio físico e social, dando origem a um projeto que constitui, na prática, verdadeiro trabalho de conclusão de curso. De posse desse projeto, o produtor rural tem à sua disposição valioso instrumento que, aplicado, deverá apoiá-lo no processo de desenvolvimento sustentável de sua propriedade, podendo servir também de modelo multiplicador para seus vizinhos.

Este artigo objetiva apresentar os princípios em que se baseia a didática e a prática dessa disciplina, assim como relatar resultados e experiências adquiridas, como proposta ímpar e pioneira no ensino das Ciências Agrárias no Brasil.

\section{ORGANIZAÇÃO DA DISCIPLINA E MÉTODO DE ENSINO}

A disciplina Planejamento Integrado de Uso da Terra apresenta características que a diferenciam do comum das disciplinas de um curso universitário 
(Giasson et al., 1995; Schneider, 1996). Seu corpo docente é formado por grande número de professores que atuam, em conjunto, tanto em sala de aula como nas atividades de campo. Às aulas formais, sucedem-se encontros de discussão e trocas de experiências cuja a tônica é a participação efetiva de discentes, docentes, proprietários rurais, técnicos das instituições de crédito e assistência rural, dirigentes sindicais, representantes de agremiações da sociedade organizada e dos governos municipais onde se situam as propriedades em estudo.

Os principais tópicos de discussão e ações giram em torno do planejamento conservacionista de uso da terra, da descrição e avaliação das características dos solos e do ambiente para uso agrícola, amostragens, cadastro dos meios de produção, elaboração de quadros-guia, modelos e instrumentos de sistematização para indicação de uso das terras, interpretação de análises laboratoriais, estudos de viabilidade técnica e econômica da exploração agropecuária, acesso a crédito, qualidade de vida do agricultor e da sua família.

O objetivo da disciplina é o da integração dos conhecimentos específicos de Solos com os demais adquiridos durante o Curso de Agronomia, de maneira prática e objetiva, buscando, por meio do estudo de casos, reavivar conhecimentos e validálos perante situações reais e aplicá-los em propostas de soluções para as propriedades selecionadas.

No decorrer do semestre, os estudantes desenvolvem, ainda, nas práticas de campo e de sala de aula, habilidades, tais como: liderança, iniciativa, criatividade, espírito crítico, capacidade de trabalhar em grupo e, o que é fundamental para sua futura atividade profissional, a capacidade de diálogo e entendimento com os agricultores, com as autoridades locais e com as comunidades. Exercita o estudante a atividade profissional, sem o compromisso formal do agrônomo e dispondo do apoio dos professores, dos colegas e da infra-estrutura da Faculdade a que pertence.

Estruturalmente, a disciplina tem um professor coordenador é lecionada por um grupo de professores do Departamento de Solos que inclui profissionais de diferentes áreas de atuação dentro da Ciência do Solo (pedologia, fertilidade do solo, conservação do solo, manejo do solo, biologia do solo), além de professores da área de mecanização agrícola, hidrologia e sedimentologia. A turma, com, no máximo, 40 alunos é normalmente dividida em dois ou três grupos de trabalho, dependendo do número de matriculados. Cada grupo dedica-se ao planejamento de uma propriedade agrícola diferente.

As propriedades rurais, objeto de planejamento, são selecionadas previamente pelo grupo de professores, considerando os seguintes fatores: necessidade de suporte técnico, variabilidade dos recursos naturais, diversidade da exploração, nível de vida e interesse do produtor no desenvolvimento do projeto, tamanho e localização geográfica da propriedade agrícola e sua representatividade na região. O importante é que a escolha da propriedade contemple a expectativa didática da disciplina (cumprimentos dos requisitos em um semestre letivo) e a expectativa dos agentes de extensão (normalmente da EMATER/RS-ASCAR), no que diz respeito à representatividade $\mathrm{da}(\mathrm{s})$ propriedade $(\mathrm{s}) \mathrm{em}$ termos de tamanho, sistemas de cultura e, ou, criação, recursos naturais e principais problemas técnicos a serem sanados.

No entanto, tem-se uma limitação séria nessa escolha no que diz respeito à distância das propriedades da Faculdade de Agronomia. Tem-se regularmente usado como critério de escolha que as propriedades devam estar dentro de um raio de $120 \mathrm{~km}$ de distância de Porto Alegre, a fim de que não seja despendido muito tempo com deslocamentos. Desse modo, muitos ecossistemas importantes e representativos do Estado ainda não puderam ser estudados com a filosofia da disciplina por situaremse fora deste raio de ação.

Os alunos são avaliados na disciplina, considerando os seguintes critérios: (1) nota de prova escrita (com vistas em verificar o envolvimento do aluno no trabalho do grupo); (2) avaliação do relatório escrito; e (3) participação nos trabalhos do grupo, considerando sua atuação objetiva e independentemente: (a) freqüência nas viagens de campo, (b) participação e discussão nos trabalhos de campo, (c) participação nas discussões em sala de aula, (d) participação nas atividades específicas dentro do grupo e (e) postura profissional.

O desenvolvimento da Disciplina compreende várias etapas: caracterização regional, levantamento dos recursos naturais existentes na propriedade, avaliação do potencial de uso agrícola das terras, levantamento do seu uso atual, diagnóstico do sistema produtivo com vistas na identificação da lógica do gerenciamento, do uso conflitivo e das potencialidades, constituição do grupo familiar, força de trabalho, qualidade de vida, elaboração da proposta de exploração sustentável da propriedade, do relatório final e sua apresentação, com a presença da comunidade local.

Na caracterização regional, procura-se desenvolver a habilidade do estudante em estabelecer relações de competência com a propriedade em estudo, buscando inseri-la na complexidade ambiental, econômica e social da região, valendo-se de dados gerais, tais como: clima, solos, recursos hídricos, vegetação predominante, distribuição fundiária, topografia, rede viária e mercado.

A etapa seguinte, do levantamento dos recursos naturais, visa exercitar, com o aluno, a habilidade de avaliar o potencial e as limitações para o uso sustentável da propriedade. Nessa etapa, são levantados os tipos de solos existentes, coletadas amostras para a avaliação da fertilidade, identificados 
e amostrados mananciais e recursos hídricos, delimitadas as diferentes glebas com mesma vocação de uso (aptidão agrícola), seu uso atual, declividades, comprimentos de rampas e vegetação.

O estudo e a organização dos dados levantados dão origem ao diagnóstico da exploração que, naturalmente, ressalta os usos conflitivos das terras e os potenciais que nortearão a etapa seguinte, do planejamento agronômico. A habilidade requerida nessa etapa é a da familiaridade do estudante com o estoque tecnológico disponível, capaz de satisfazer as necessidades levantadas nas etapas anteriores. É nessa etapa que os estudantes valem-se de todos os conhecimentos adquiridos durante o curso de Agronomia. É o momento de buscar relações entre os diferentes saberes, geralmente apropriados isoladamente, sistematizando-os e dando-lhes pertinência.

$\mathrm{Na}$ etapa de elaboração e apresentação do relatório final, é exercitada a habilidade da redação técnica, da apresentação oral, do debate e capacidade do convencimento frente à comunidade local.

Para melhor entendimento, as diversas etapas da disciplina são explicitadas a seguir.

\section{Etapa 1: Caracterização regional}

Visa treinar os alunos no acesso às fontes de informação e dar-lhes conhecimento adequado e sustentado sobre a realidade regional. Na primeira semana do semestre, é solicitada aos alunos a realização de pesquisa a respeito de informações sobre a região e município onde as propriedades a serem planejadas estão inseridas. Assim, já na primeira visita à(s) propriedade(s) rural(is), os alunos estarão adequadamente informados sobre a realidade regional. O material obtido nesta etapa do trabalho será posteriormente incluído no relatório final do projeto de planejamento agrícola e, normalmente, inclui informação sobre localização geográfica, clima, solo, geologia, história do desenvolvimento regional, principais culturas cultivadas, disponibilidade de mão-de-obra, organizações administrativas (municipal e regional), associações, sindicados e empresas de extensão rural atuantes na região, mercado agrícola regional, população, etnias dominantes na região e malha viária.

\section{Etapa 2: Levantamento dos recursos naturais}

Após um período correspondente às duas primeiras semanas de aula, quando a disciplina é apresentada aos alunos e alguns aspectos práticos de disciplinas já cursadas são relembrados, acontecem duas viagens para o desenvolvimento do trabalho prático em campo. Estas duas viagens são intercaladas com uma semana para discussão da primeira etapa dos trabalhos em sala. Nestas viagens, os alunos elaboram o diagnóstico dos recursos naturais disponíveis na propriedade (solo, água e vegetação), constituindo o mapeamento de áreas diferenciadas da propriedade, dos tipos de solos e do uso atual das terras; no inventário de estruturas físicas e de máquinas e equipamentos disponíveis e na amostragem de solo para avaliação da sua fertilidade. Este trabalho é feito pelo encaminhamento geral da propriedade para reconhecimento da área e dos seus limites físicos e pelo mapeamento de variações em tipos de solos e de características limitantes ao uso da terra (tais como drenagem, pedregosidade, declividade e risco de inundação), além de sua caracterização em relação à sua posição geográfica dentro da bacia hidrográfica. Aspectos relacionados com o uso, manejo e conservação do solo são observados. Amostras de água são coletadas e encaminhadas para laboratório a fim de ser avaliada a qualidade físicoquímica e biológica da água disponível e consumida nas propriedades. Resíduos orgânicos (estercos, estrumes e compostos) são coletados a fim de serem analisados. Todas as construções da propriedade são medidas e avaliadas. Máquinas e equipamentos são inventariados e avaliados. Amostras compostas de solo de cada área da propriedade são coletadas para análise da fertilidade do solo e futura recomendação de corretivos e fertilizantes.

Na avaliação da propriedade, além de considerar as condições naturais do meio físico, as quais definem o potencial de uso agrícola das terras (geologia, solo, relevo, clima e vegetação natural), também são avaliadas as facilidades e dificuldades estruturais do meio (vias de acesso, distância a centros de consumo e abastecimento) e aspectos sócioeconômicos importantes para o planejamento agrícola. Sempre que possível, são utilizadas tecnologias como fotografias aéreas, GPS, imagens de sensoriamento remoto e altímetro, o que tem facilitado o trabalho de campo e, muitas vezes, enriquecido o trabalho em termos de disponibilização e precisão de informações.

\section{Etapa 3: Diagnóstico do sistema de produção da propriedade}

A informação coletada em campo é organizada e analisada pelos alunos com auxílio dos professores. Os mapas produzidos e as informações coletadas, assim como suas interpretações, são discutidos em grupo e, posteriormente, entregues aos professores para avaliação. Esse conjunto de informações é utilizado para que os alunos organizem quadrosguias com vistas em avaliar o mapeamento da aptidão agrícola das terras e o estabelecimento de glebas para o planejamento de uso do imóvel. Com a disponibilidade destas informações, os grupos de alunos avaliam os potenciais e as limitações das diferentes glebas das propriedades, identificando conflitos de uso e considerando possíveis recomendações de melhoria do processo produtivo. 
Em seguida, o trabalho é desenvolvido, durante algumas semanas (5 a 7 semanas, normalmente) pelos alunos fora do horário de aula por meio de reuniões de trabalho dos grupos. No entanto, semanalmente, são apresentados os resultados parciais em sala de aula aos professores e aos colegas dos demais grupos. Nestas atividades, além da discussão qualitativa do trabalho apresentado, procura-se desenvolver habilidades nos alunos quanto à elaboração de apresentações, utilizando equipamentos de multimídia, uso de linguagem e vocabulário adequado, postura e ética profissionais e treinamento para trabalho em equipe.

A fim de obter mais informações sobre a realidade da produção agrícola local, durante a fase de diagnóstico, os alunos estabelecem contatos com o corpo técnico da região (agrônomos, veterinários, zootecnistas e técnicos agrícolas), com o corpo administrativo da região e município (prefeitos, vereadores, secretários municipais, dirigentes de sindicatos e associações) e com outras organizações, associações ou empresas públicas e privadas. É através da busca de informações com essas organizações que os alunos entendem melhor a realidade local e formam conceito mais realista do processo produtivo regional.

A próxima visita à propriedade visa possibilitar aos alunos entrevistar o agricultor e sua família, a fim de conhecer seus anseios e necessidades. Isso permite que no planejamento seja considerada a realidade do processo produtivo na propriedade e que sejam sugeridas práticas que realmente atendam às expectativas do produtor e que possam ser por ele implementadas.

Essa entrevista possibilita aos alunos a oportunidade para que muitas questões surgidas durante o levantamento dos recursos (fase de diagnóstico) sejam respondidas. Por sua vez, na entrevista, o agricultor tem a oportunidade de demonstrar seus anseios, receios e valores culturais, informações indispensáveis para que os alunos possam planejar a propriedade agrícola de forma adequada. Ademais, a entrevista serve como forma de treinamento aos alunos de como proceder numa entrevista e abordagem de produtores rurais, adequando a linguagem e a forma de tratamento interpessoal.

\section{Etapa 4: Elaboração das proposições}

Após o diagnóstico dos recursos naturais da propriedade e das entrevistas, o trabalho entra na etapa de planejamento propriamente dita. Nesta etapa, o grupo de alunos deve buscar soluções e idéias práticas a serem propostas para a propriedade, que devem ser realistas e executáveis. A diversidade do uso agrícola das terras leva à procura de soluções diferentes, o que obriga os alunos a terem uma visão sistêmica e a resgatar os conhecimentos específicos adquiridos durante o Curso de Agronomia.
Baseados nos recursos do quadro-guia (Hesseln, 1997; Neubert, 1995; Streck, 1992) e da Equação Universal de Perdas de Solo (EUPS) (Wischmeier \& Smith, 1978), há possibilidade de confrontar o uso atual com a aptidão agrícola das glebas e de estimar as perdas de solo por erosão. Para organizar o quadro-guia, utilizam-se fatores limitantes de uso da terra de difícil correção e que são determinantes para esta avaliação, a saber: declividade, profundidade do solo, pedregosidade, drenagem, textura do solo e risco de inundação. Na elaboração do quadro-guia, estas características são organizadas em classes com vistas em estabelecer todas as combinações possíveis entre as diversas classes de características limitantes. Para cada uma das combinações, baseado em informações de pesquisa em uso, manejo e conservação do solo, em discussão entre os técnicos que atuam na região e na experiência de agricultores, indicam-se a classe e a subclasse aptidão de uso das terras.

Nesse contexto, a EUPS, que avalia o potencial de perdas por erosão, considerando fatores topográficos, climáticos e fatores relacionados com o uso e manejo da terra, é utilizada como um instrumento, tanto para avaliar as perdas de solo potenciais atualmente ocorrentes na área em estudo, como para prever perdas potenciais com os usos propostos.

O quadro-guia permite mapear a aptidão e elaborar a legenda do mapa de aptidão de uso das terras que, quando comparado ao uso atual da terra, permite determinar as áreas de conflitos de uso da terra, as quais serão o foco principal de atenção no planejamento. Nos locais de uso conflitivo, ou seja, nos locais onde o solo está sendo utilizado fora de sua aptidão agrícola, há necessidade de adequar o sistema de culturas, a forma de manejo do solo ou ambos. Em todas as situações, será necessário o uso de conhecimentos específicos das diversas áreas da Agronomia, não somente de Solos, para propor soluções.

Durante esta fase, além de inúmeras reuniões, os alunos devem, semanalmente, informar o progresso de suas propostas de planejamento aos professores, por meio de apresentações orais. Desta forma, embora o planejamento seja feito pelos alunos, o acompanhamento progressivo das propostas permite aos professores não só questionar e orientar o trabalho dos alunos, a fim de que eles possam propor soluções adequadas, justificando e defendendo-as tecnicamente, mas também identificar áreas ou setores do conhecimento agronômico em que os alunos deverão buscar fundamentos para embasar suas propostas. Neste aspecto, é freqüente que os alunos resgatem materiais didáticos de disciplinas já cursadas e consultem professores da Faculdade de Agronomia e outros da Universidade para dirimir dúvidas, confrontar ou avalisar suas propostas. 


\section{Etapa 5: Elaboração do relatório final e apresentação dos resultados}

O produto final do planejamento das propriedades é um relatório técnico que é entregue no final do semestre aos professores, aos proprietários rurais e aos técnicos extensionistas da região. O relatório final representa, portanto, a integração dos conhecimentos específicos da área de Solos com as demais ministradas no Curso de Agronomia, de maneira aplicada, prática e objetiva, reavivando conhecimentos e validando-os em situação de realidade.

A entrega dos relatórios é acompanhada de apresentação das propostas pelos alunos em palestra aos agricultores e técnicos nas propriedades agrícolas ou em espaços públicos mais amplos, sendo aberta a todo o público interessado, com prévia divulgação local do evento. Nesta ocasião, os alunos têm a oportunidade de apresentar as propostas de uso e manejo das propriedades agrícolas aos agricultores, ao mesmo tempo que podem justificar estas propostas e responder questões dos técnicos e agricultores.

\section{RESULTADOS E DISCUSSÃO}

Durante os 12 anos de adoção da disciplina, sob coordenação de diversos professores do Departamento de Solos, já passaram por essa experiência didática 358 alunos, tendo sido planejadas 34 propriedades agrícolas, das quais dependem economicamente aproximadamente 80 famílias. O número médio de alunos por turma foi de 13, e o número médio de professores envolvidos na disciplina foi de seis por semestre.

A variabilidade dos tipos de situações produtivas já analisadas e planejadas caracteriza-se por: pequena e média propriedade (7 a $320 \mathrm{ha}$ ), propriedades particulares, propriedades arrendadas, propriedades exploradas por meeiros e por agricultores assentados pelo processo de reforma agrária. A área total planejada foi de 1.365 ha, com média de 40 ha por grupo e de 57 ha por semestre. As propriedades agrícolas planejadas variam desde pequenas propriedades familiares com agricultura de subsistência até empresas rurais. Também já foram planejados assentamentos rurais respectivamente com cinco e com cinqüenta famílias. O perfil das propriedades planejadas mostra que os alunos do curso já ajudaram a planejar propriedades antigas e com tradição na atividade agrícola, que apresentavam problemas no processo produtivo e tinham sua sustentabilidade ameaçada, da mesma forma que ajudaram no planejamento de propriedades recémadquiridas, como foi o caso de planejamento de algumas propriedades adquiridas pelo Banco da Terra e por instituições governamentais para fins de assentamentos agrícolas.
Uma síntese do desenvolvimento da disciplina neste período pode ser visualizada no quadro 1 . Exemplos de relatórios de planejamento elaborados durante a disciplina são de Schneider et al. (1994), Souza et al. (1995), Giasson et al. (1997a, b) e Pezzi et al. (1997).

Os municípios já atendidos concentram-se nas proximidades da região metropolitana de Porto Alegre, dos quais alguns já foram atendidos mais de uma vez. Essa variedade de localidades faz com que as propriedades planejadas localizem-se sob condições climáticas variáveis e em condições diversas de geologia, solos, topografia e drenagem. Além disso, dada a variabilidade cultural da população rural do Estado, os estudantes tiveram a oportunidade de trabalhar com produtores rurais de diversas etnias e diversificado conjunto de valores culturais, enriquecendo a convivência e o aprendizado.

Tipos de culturas e usos da terra avaliados e propostos pelos alunos incluem plantas frutíferas, olericultura, culturas anuais (milho, feijão, trigo, aveia, sorgo, soja, girassol e outros), pastagens naturais e melhoradas, além de criações animais, tais como: gado leiteiro, gado de corte, cabras, ovelhas, porcos, abelhas e peixes. Cabe ressaltar que todas as proposições feitas pelos estudantes são acompanhadas de um demonstrativo econômico, a fim de comprovar sua viabilidade nas propriedades.

Professores de outras áreas de estudo, embora tenham sido convidados a participar da disciplina desde o início, só eventualmente isso ocorreu. Quando ocorreu, esta colaboração foi extremamente benéfica ao desenvolvimento dos trabalhos. Entretanto, por ser a disciplina de responsabilidade do Departamento de Solos, nem sempre foi encontrada disponibilidade para esta interação.

Freqüentemente, com a participação dos técnicos ou de outros líderes locais, as propostas sugeridas especificamente às propriedades planejadas passam a receber difusão, de forma que o planejamento feito pelos alunos passa a ter uma importância regional. A metodologia utilizada na disciplina muitas vezes é adaptada pelos técnicos dos municípios ou da região para elaboração de projetos, relatórios de instituições financiadoras, como BIRD, PRONAF, RS Rural, Reforma Agrária, métodos para estabelecimento de índices (diferenciação do valor da terra, lotação animal, teto de produtividade). Novas tecnologias, como GPS, sensoriamento remoto, têm demandado cursos para capacitação técnica. O mesmo vale para mecanização, classificação dos solos, conservação dos solos, manejo dos solos, manejo e disposição de dejetos orgânicos.

Mesmo sendo uma disciplina de três créditos (carga horária total de 45 horas-aula), a disciplina, nos atuais moldes de abrangência e profundidade, não consegue cumprir as tarefas neste período de tempo. No entanto, as atividades dos alunos e dos 
Quadro 1. Caracterização das propriedades e grupos de trabalho participantes da disciplina

\begin{tabular}{|c|c|c|c|c|c|c|}
\hline $\begin{array}{c}\text { Ano/ } \\
\text { semestre }\end{array}$ & Município & Propriedade & Área & Principais culturas ou atividades & $\begin{array}{l}\text { Professores por } \\
\text { propriedade }\end{array}$ & $\begin{array}{c}\text { Alunos por } \\
\text { propriedade }\end{array}$ \\
\hline & & & ha & & & \\
\hline $1992 / 2$ & Paverama & 1 & 25 & $\begin{array}{l}\text { Bovinocultura de leite, suinocultura, } \\
\text { milho, pastagem }\end{array}$ & 5 & 12 \\
\hline $1993 / 1$ & Paverama & 1 & 25 & $\begin{array}{l}\text { Bovinocultura de leite, suinocultura, } \\
\text { milho, pastagem }\end{array}$ & 6 & 14 \\
\hline $1993 / 2$ & Teutônia & 1 & 35 & $\begin{array}{l}\text { Bovinocultura de leite, suinocultura, } \\
\text { milho, pastagem }\end{array}$ & 8 & 15 \\
\hline \multirow[t]{2}{*}{$1994 / 1$} & Barra do Ribeiro & 1 & 7 & Batata doce & 7 & 8 \\
\hline & Barra do Ribeiro & 2 & 16 & Turismo rural, caprinocultura & 3 & 6 \\
\hline \multirow[t]{2}{*}{$1994 / 2$} & Barra do Ribeiro & 1 & 22 & $\begin{array}{l}\text { Milho, arroz, bovinocultura, } \\
\text { pastagem }\end{array}$ & 6 & 8 \\
\hline & & 2 & 135 & $\begin{array}{l}\text { Arroz, milho, bovinocultura, } \\
\text { olericultura }\end{array}$ & 7 & 19 \\
\hline \multirow[t]{2}{*}{$1995 / 1$} & Nova Santa Rita & 1 & 22 & $\begin{array}{l}\text { Bovinocultura, pastagem, } \\
\text { avicultura, milho }\end{array}$ & 8 & 10 \\
\hline & Capela Santana & 2 & 320 & Arroz, avicultura & 6 & 12 \\
\hline $1995 / 2$ & Porto Alegre & 1 & 13 & $\begin{array}{l}\text { Avicultura, suinocultura, } \\
\text { fruticultura }\end{array}$ & 5 & 8 \\
\hline $1996 / 1$ & Porto Alegre & 1 & 15 & Olericultura & 8 & 12 \\
\hline $1996 / 2$ & Viamão & 1 & 30 & $\begin{array}{l}\text { Olericultura, fruticultura, milho, } \\
\text { mandioca }\end{array}$ & 7 & 7 \\
\hline \multirow[t]{2}{*}{$1997 / 1$} & Porto Alegre & 1 & 15 & Olericultura, fruticultura & 6 & 5 \\
\hline & & 2 & 43 & Milho, bovinocultura, pastagem & 6 & 5 \\
\hline $1997 / 2$ & Sapiranga & 1 & 37 & Acácia, mandioca, milho & 7 & 10 \\
\hline $1998 / 1$ & Porto Alegre & 1 & 18 & Olericultura & 9 & 13 \\
\hline $1998 / 2$ & Sentinela do Sul & & 94 & $\begin{array}{l}\text { Milho, mandioca, arroz, } \\
\text { bovinocultura, fumo }\end{array}$ & 7 & 31 \\
\hline $1999 / 1$ & Barra do Ribeiro & 1 & 42 & $\begin{array}{l}\text { Arroz, milho, bovinocultura, cana- } \\
\text { de-açucar, fumo, bovinocultura de } \\
\text { corte, pastagem }\end{array}$ & 8 & 14 \\
\hline $1999 / 2$ & Sentinela do Sul & 1 & 94 & $\begin{array}{l}\text { Milho, mandioca, arroz, } \\
\text { bovinocultura, fumo, pastagem }\end{array}$ & 8 & 28 \\
\hline \multirow[t]{2}{*}{$2000 / 1$} & Fazenda Vilanova & 1 & 70 & Soja trigo, feijão & 9 & 12 \\
\hline & & 2 & 35 & $\begin{array}{l}\text { Bovinocultura de leite, milho, } \\
\text { pastagem }\end{array}$ & 9 & 10 \\
\hline $2000 / 2$ & Fazenda Vilanova & 1 & 36 & $\begin{array}{l}\text { Bovinocultura de leite, milho, } \\
\text { pastagem }\end{array}$ & 8 & 13 \\
\hline \multirow[t]{2}{*}{$2001 / 1$} & Teutônia & 1 & 24 & $\begin{array}{l}\text { Milho, soja, bovinocultura de leite, } \\
\text { suinocultura. Suínos, pastagem }\end{array}$ & 4 & 8 \\
\hline & Fazenda Vilanova & 2 & 36 & $\begin{array}{l}\text { Bovinocultura de leite, milho, } \\
\text { pastagem }\end{array}$ & 4 & 10 \\
\hline \multirow[t]{2}{*}{$2001 / 2$} & Barão do Triunfo & 1 & & $\begin{array}{l}\text { Cana-de-açúcar, fumo, bovinocultura } \\
\text { de corte, pastagem }\end{array}$ & 4 & 28 \\
\hline & & 2 & & Batata doce e fumo & 3 & 17 \\
\hline \multirow[t]{2}{*}{$2002 / 1$} & Osório & 1 & 15 & Olericultura & 5 & 13 \\
\hline & & 2 & 10 & Cana-de-açúcar, milho & 5 & 13 \\
\hline \multirow[t]{2}{*}{$2002 / 2$} & $\begin{array}{l}\text { Santo Antônio da } \\
\text { Patrulha }\end{array}$ & 1 & 18 & $\begin{array}{l}\text { Bovinocultura de leite, milho, } \\
\text { pastagem }\end{array}$ & 3 & 16 \\
\hline & & 2 & 12 & $\begin{array}{l}\text { Bovinocultura de leite, milho, } \\
\text { pastagem }\end{array}$ & 4 & 19 \\
\hline \multirow[t]{2}{*}{$2003 / 1$} & Teutônia & 1 & 44 & $\begin{array}{l}\text { Bovinocultura de leite, milho, } \\
\text { pastagem }\end{array}$ & 6 & 10 \\
\hline & Teutônia & 2 & 19 & $\begin{array}{l}\text { Bovinocultura de leite, milho, } \\
\text { pastagem }\end{array}$ & 5 & 13 \\
\hline \multirow[t]{3}{*}{$2003 / 2$} & $\begin{array}{l}\text { Santo Antônio da } \\
\text { Patrulha }\end{array}$ & 1 & 14 & Cana-de-açúcar e turismo rural & 4 & 10 \\
\hline & & 2 & 24 & $\begin{array}{l}\text { Cana-de-açúcar e leite, milho, } \\
\text { pastagem }\end{array}$ & 3 & 11 \\
\hline & & 3 & 16 & $\begin{array}{l}\text { Cana-de-açúcar e leite, milho, } \\
\text { pastagem }\end{array}$ & 3 & 11 \\
\hline \multirow[t]{2}{*}{$2004 / 1$} & São José do Hortêncio & 1 & 19 & $\begin{array}{l}\text { Bovinocultura de leite, milho, aveia, } \\
\text { azevém, citrus, pastagem }\end{array}$ & 5 & 8 \\
\hline & São José do Hortêncio & 2 & 14 & $\begin{array}{l}\text { Bovinocultura de leite, milho, aveia, } \\
\text { cana-de-açúcar, azevém, pastagem }\end{array}$ & 4 & 7 \\
\hline
\end{tabular}


professores vão além das 45 h por semestre, visto que, para formulação do diagnóstico e das recomendações e posterior avaliação do material escrito, há demanda de, no mínimo, mais 20 horasaula por semestre. Essa carga horária adicional tem sido considerada como participação em projeto de extensão, com a participação dos professores e alunos. Este projeto de extensão é classificado como "Estudo de Caso em Planejamento Integrado de Uso da Terra".

Para o bom andamento e desempenho da disciplina, é necessário contar com a participação efetiva de todos os professores, disponibilidade de propriedades agrícolas adequadas para os fins da disciplina, disponibilidade e flexibilidade de meio de transporte para o grupo (ônibus) e disponibilidade de recursos para pagamento de combustível, análises de solo, de água e de resíduos. No final de cada semestre, é feita uma avaliação da disciplina por meio de reunião dos alunos e professores envolvidos. Afora pequenas sugestões de melhorias na sua forma de condução, a disciplina tem recebido completa aprovação e estímulo do grupo de estudantes envolvidos. Ademais, a disciplina tem recebido apoio por parte dos agricultores, do corpo técnico e dos administradores das comunidades onde o trabalho tem sido desenvolvido. Este apoio freqüentemente tem sido manifestado na forma de solicitação para que a disciplina seja desenvolvida dentro de municípios onde ex-alunos atuam profissionalmente, ou em municípios vizinhos aos já trabalhados por estes terem tido alguma informação sobre a atividade. Também, em visitas efetuadas pelos professores a algumas propriedades objeto de planejamento da disciplina, verificaram-se vários graus de adoção das propostas. Verifica-se que, na maioria das propriedades, houve adoção parcial ou total das proposições sugeridas pelos alunos, enquanto, em outras, não houve concretização das proposições.

Nesse contexto, e considerando o sucesso alcançado, nos próximos anos, a atual disciplina de Planejamento Integrado de Uso da Terra será substituída por outra mais abrangente, denominada Planejamento Agronômico Integrado.

\section{CONCLUSÕES}

1. A avaliação geral da experiência com a disciplina tem sido extremamente positiva sob vários aspectos. Em primeiro lugar, a disciplina tem possibilitado aos estudantes exercitar a visão de síntese dos conhecimentos, que foram adquiridos de forma fragmentada. Aliado a esse aspecto, soma-se a possibilidade de que, sendo o trabalho feito com agricultores, os estudantes assumam uma postura profissional e exercitem as habilidades que foram desenvolvidas durante o curso, porém contando ainda com a orientação do professor. O fato de os estudantes poderem ter essa experiência antes de concluírem o curso de Agronomia faz com que eles adquiram maior confiança na sua capacidade profissional em um momento bastante crítico de sua carreira, que é o momento que antecede a sua finalização do curso superior.

2. Outro aspecto relevante dessa experiência é a possibilidade de os estudantes terem contato com a realidade da agricultura familiar brasileira e identificar seus principais problemas e limitações. Esta condição faz com que os estudantes sejam estimulados a buscar e discutir com os agricultores soluções agronômicas socialmente apropriadas, possibilitando que os futuros profissionais possam atuar como agentes do desenvolvimento.

\section{AGRADECIMENTOS}

Os autores agradecem a todos os agricultores e proprietários rurais que contribuíram decisivamente para o desenvolvimento desta disciplina, assim como entidades públicas e privadas que têm apoiado este trabalho nos processos de seleção de áreas e discussão dos planejamentos propostos. Agradecimento especial aos chefes de departamentos e diretores da Faculdade de Agronomia, pelos recursos concedidos, e, particularmente, a todos os professores que participaram da disciplina e que muito contribuíram para que ela pudesse evoluir e cumprir sua função.

\section{LITERATURA CITADA}

BECK, F.L.; BOHNEN, H.; CABEDA, M.S.V.; CAMARGO, F.A.O.; KÄMPF, N. \& MEURER, E.J. Projeto pedagógico de ensino de graduação. Departamento de Solos, Porto Alegre, Universidade Federal do Rio Grande do Sul, 2000. 26p. (Boletim Técnico, 6)

GIASSON, E.; SOUZA, L.F. C.; LEVIEN, R.; SCHNEIDER, P.; COGO, N.P.; BOHNEN, H.; CASSOL, E.A. \& BISSANI, C.A. Planejamento Integrado de Uso da Terra - uma experiência didática no Departamento de Solos da UFRGS. In: CONGRESSO BRASILEIRO DE CIÊNCIA DO SOLO, 25, Viçosa, 1995. Anais. Viçosa, Sociedade Brasileira de Ciência do Solo., 1995. p.2195-2197.

GIASSON, E.; NASCIMENTO, P.C.; BOHNEN, H.; SOUZA, L.F.C.; TREIN, C.R. \& SCHNEIDER, P. Planejamento de uso da propriedade rural do Sr. Maciel Fernando Lahud localizada no Município de Viamão, RS. Porto Alegre, Universidade Federal do Rio Grande do Sul, 1997a. (Relatório Técnico)

GIASSON, E.; TREIN, C.R.; NASCIMENTO, P.C.; SCHOLLES, D. \& GIANELLO, C. Planejamento do uso da propriedade rural dos irmãos Steffani, de 43 hectares, localizada no Município de Porto Alegre. Porto Alegre, Universidade Federal do Rio Grande do Sul, 1997b. (Relatório Técnico) 
HESSELN, N.E. Levantamento de solos e avaliação da aptidão agrícola das terras do Assentamento Capela (Nova Santa Rita/RS). Porto Alegre, Universidade Federal do Rio Grande do Sul, 1997. 109p. (Tese de Mestrado)

NEUBERT, E.O. Levantamento de solos e avaliação do potencial de uso agrícola das terras da microbacia do Arroio Armazém (Município de Urussanga, SC). Porto Alegre, Universidade Federal do Rio Grande do Sul, 1995. 127p. (Tese de Mestrado)

PEZZI, E.; BAUER, F.; SCHAFER, G.; AMARAL, L.; GIASSON, E.; TREIN, C.R.; GIANELLO, C.; SCHOLLES, D.; SOUZA, L.F.C. \& NASCIMENTO, P.C. Planejamento do uso da propriedade rural dos Srs. Vanderlei Steffani e José R. Steffani de 43 hectares localizada no município de Porto Alegre, Universidade Federal do Rio Grande do Sul, 1997. (Relatório Técnico)

SCHNEIDER, P.; LEVIEN, R.; COGO, N.P.; GIASSON, E. \& SOUZA, L.F.C. Planejamento de uma propriedade rural de 135 hectares situada no Assentamento de Capela de Santana, Rio Grande do Sul. Porto Alegre, Universidade Federal do Rio Grande do Sul, 1994. (Relatório Técnico)
SCHNEIDER, P. A disciplina "Planejamento Integrado de Uso da Terra": uma prática pedagógica na produção do conhecimento. In: SIMPÓSIO BRASILEIRO SOBRE ENSINO DE SOLOS, 2., Santa Maria, 1995. Anais. Santa Maria, Sociedade Brasileira de Ciência do Solo, 1996. p.115122.

SOUZA, L.F.C.; CASSOL, E.A.; GIASSON, E.; COGO, N.P.; SCHNEIDER, P. \& LEVIEN, R. Planejamento de uma propriedade rural de 20 hectares do Assentamento Capela de Santana, Município de Nova Santa Rita, Rio Grande do Sul. Porto Alegre, Universidade Federal do Rio Grande do Sul, 1995. (Relatório Técnico)

STRECK, E.V. Levantamento de solos e avaliação do potencial de uso agrícola das terras da microbacia do Lajeado Atafona (Santo Ângelo - RS). Porto Alegre, Universidade Federal do Rio Grande do Sul, 1992. 167p. (Tese de Mestrado)

WISCHMEIER, W.H. \& SMITH, D.D. Predicting rainfall erosion losses - a guide to conservation planning. Washington, USDA: U.S. Government Printing Officie, 1978. 58p. (Agricultural Handbook, 537) 